\title{
Presencia de la celdilla supra-órbito-etmoidal. Revisión de la literatura a partir de un caso
}

\author{
Presence of supraorbital ethmoid cell. Literature review from a case
}

Rodolfo Nazar $\mathbf{S}^{1}$, Daniel Retuert $\mathbf{R}^{1}$, M Francisca Frías $\mathbf{E}^{2}$, Gonzalo Miranda $\mathbf{G}^{3}$, Alfredo Naser $\mathbf{G}^{1}$.

\begin{abstract}
RESUMEN
La celdilla supra-órbito-etmoidal es una variación anatómica que se presenta con diferente frecuencia para las distintas poblaciones. Representa un desafío al realizar cirugía endoscópica funcional del seno frontal debido a que su presencia dificulta el drenaje adecuado del receso del frontal mismo y puede ser confundida con el seno. La celdilla supra-órbito- etmoidal presenta relaciones espaciales constantes con la arteria etmoidal anterior, sirviendo como marcador anatómico confiable para el abordaje quirúrgico. Se destaca la importancia de considerar la presencia de tabiques óseos en el seno frontal en el estudio imagenológico que puedan sugerir la presencia de la celdilla supra-órbito-etmoidal. Se presenta el caso clínico de un paciente que consulta por proptosis del ojo derecho debido a un proceso expansivo por mucocele localizado en dicha variante anatómica.
\end{abstract}

Palabras clave: Etmoidal, celdilla, mucocele, cirugía endoscópica.

\begin{abstract}
The supraorbital ethmoid cell its an anatomical variation with different frecuency for diverse populations. It represents a challenge for the endoscopical functional :surgery of the frontal sinus. The supraorbital ethmoid cell presents an estable anatomical relationship with the anterior ethmoidal artery, serving as a dependable anatomical marker for the surgical approach. We stand out the importance to consider the presence of bony septations in the frontal sinus that might suggest the presence of the supraorbital ethmoid cell. We introduce a clinical case from a patient who had an expansive process from a mucocele in the supraorbital ethmoid cell.
\end{abstract}

Key words: Ethmoidal, cell, mucocele, endoscopical surgery.

\footnotetext{
1 Médico Otorrinolaringólogo, Hospital Clínico de la Universidad de Chile.

2 Interna Medicina sede Oriente Universidad de Chile, Cirujano Dentista Universidad de Chile.

3 Médico Neurorradiólogo, Hospital Clínico Universidad de Chile.
} 


\section{INTRODUCCIÓN}

Existen celdillas neumáticas en el complejo etmoidofrontal que constituyen marcadores para la cirugía endoscópica por ser variaciones de la anatomía. La celdilla de Haller ubicada bajo la bula etmoidal, a lo largo del piso orbitario; la celdilla de Onodi, que se encuentra superior y lateral al seno esfenoidal, en contacto con el nervio óptico, ambas con relevancia en casos de infección y complicaciones.

En el caso del complejo de celdillas etmoidales anteriores, la neumatización del hueso frontal está determinada por el crecimiento desde las mismas. De este crecimiento derivan las celdilla frontal, suprabular, frontobulares, del septo interfrontal y la celdilla supra-órbito-etmoidal (SOE) ${ }^{1}$.

La celdilla SOE fue descrita por Van Alyea en 1942. Es parte del complejo etmoidal anterior que invade la lámina supraorbitaria del hueso frontal. Está ubicada por posterior al seno frontal, superior al techo de la órbita en el hueso frontal, constituyendo una neumatización de la misma, superior y lateral a la lámina papirácea y anterior a la arteria etmoidal anterior. Su drenaje está posterior al drenaje del seno frontal ${ }^{2}$. Esto puede estrechar el drenaje del receso frontal, y puede ser confundido con el ostium frontal.

La presencia de la celdilla supra-órbito-etmoidal presenta variaciones en frecuencia en las distintas poblaciones. Es así que para la población caucásica se describe el $64,4 \%$, mientras que para la población en Corea y China se estima en $2,6 \%$ y $5,4 \%$, respectivamente ${ }^{1}$. No existe registro descrito para la población chilena, ni para la población latinoamericana.

La estrechez del drenaje del receso frontal constituiría un factor de riesgo para la presencia de mucocele en el seno frontal, esto se vería agravado cuando la presencia de la celdilla supraórbito-etmoidal dificulta aún más el drenaje del seno frontal ${ }^{6}$.

La importancia de la celdilla supra-órbito-etmoidal radicaría en que la falla del reconocimiento de la celdilla puede llevar a pensar que se alcanza el seno frontal, en forma errónea. Esta es la relevancia fundamental de esta variante anatómica.

Dentro de las complicaciones de la cirugía endoscópica nasal, se encuentra la laceración y/o desgarro de la arteria etmoidal anterior que se pue- de retraer y formar un hematoma orbitario. Entre los marcadores para la ubicación de la arteria se encuentra la distancia en relación al seno frontal y la base anterior del cráneo, pero éstos presentarían alta variabilidad en la población $n^{3}$. En la patología inflamatoria nasal severa, la identificación de la arteria sería laboriosa.

La celdilla SOE presenta una relación espacial estable con la arteria etmoidal anterior, constituyendo así un marcador consistente, aun en procesos inflamatorios.

Dicho indicador sería de gran utilidad en la ubicación de la arteria en poblaciones con alta incidencia de la celdilla SOE ${ }^{4,5}$.

La celdilla SOE es sitio de preferencia para la aparición de mucoceles, debido a la dificultad en el drenaje por la intrincada anatomía.

En el mucocele de la celdilla SOE se presenta cefalea frontal junto a signos oftalmológicos como diplopía, inflamación de los párpados superiores ${ }^{6}$. La presión causada por el aumento de volumen produce erosión en la lámina orbitaria que finalmente causa la proptosis. Existe una fuerte asociación en pacientes con proptosis y procesos expansivos en la celdilla SOE, en pacientes con rinosinusitis crónica?

En relación al estudio de imágenes, se observa que la presencia de septos en el seno frontal indicaría la existencia de la celdilla SOE. En estudio realizado por Kountakis y cols, se observa una relación significativa en la presencia de septos en el seno frontal con la presencia de celdilla SOE? .

La opacificación de la celdilla SOE puede dar la apariencia de una lesión lateral del seno frontal, por lo cual es importante tener en cuenta su presencia para el adecuado manejo quirúrgico. Los mucoceles de la celdilla SOE puede ser tratado por medio de cirugía endoscópica sinusal ${ }^{9}$.

Debido a su localización lateral, la indicación tradicional ha sido una aproximación externa, sin embargo el procedimiento Hemi-Lothrop modificado sería una técnica viable para el manejo del mucocele en la SOE.

\section{CASO CLÍNICO}

Presentamos el caso de un paciente de sexo masculino, de 44 años, sin antecedentes mórbidos, 
ni quirúrgicos. En enero de 2015 acude al Servicio de Otorrinolaringología del Hospital Clínico de la Universidad de Chile. Presentaba un aumento de volumen súpero-medial en órbita derecha de 4 meses de evolución, con proptosis intermitente en el tiempo y diplopía (Figura 1).

Los cortes sagitales y axiales del TC de CPN (Figuras 2 y 3 ) evidencian una gran celdilla supraórbito-etmoidal, que comprime el seno frontal, el cual se encuentra atelectasiado. En el corte coronal (Figura 4) se observa el mucocele de la celdilla SOE, con una dehiscencia del techo de la órbita, y compromiso intraorbitario.

En marzo de 2015 se realiza una frontotomía tipo Draf IIB con marsupialización amplia. El paciente evoluciona favorablemente con regresión del exoftalmo. Se mantiene en control seriado con

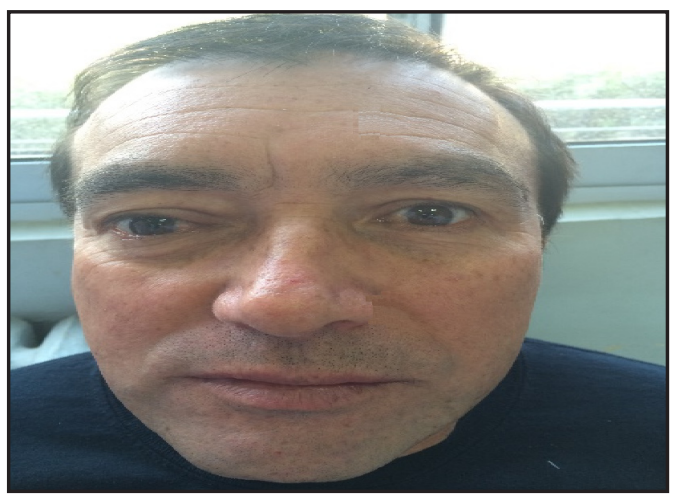

Figura 1. Se observa proptosis de ojo derecho con aumento de volumen en región súpero medial de la órbita. terapia médica, corticoides inhalatorios y lavados nasales.

En agosto de 2015 el paciente consulta por cuadro de 2 semanas de evolución, cefalea frontoorbitaria, rinorrea mucopurulenta y proptosis. A la endoscopía nasal se observan sinequias en el receso frontal. Se realiza una segunda intervención endoscópica en donde se accede a la bula etmoidal y se drena contenido mucopurulento y se vuelve a repermeabilizar la frontotomía. En controles posteriores evoluciona con cefalea de carácter progresivo y proptosis. En diciembre de 2015, en control posterior se observa sinequia y osteoneogénesis (Figura 5) que obstruye drenaje de celdilla SOE. Se programa una tercera intervención en que se mar-

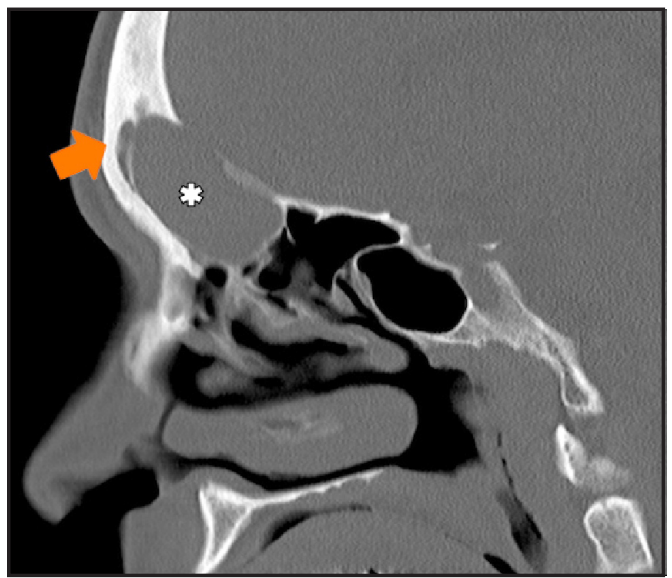

Figura 2. En el corte sagital de CPN se observa una gran celdilla supra-órbito-etmoidal (asterisco) que comprime el seno frontal atelectasiado (flecha).

Figura 3. Corte axial de CPN. Se observa expansión de la celdilla SOE (asterisco) con el remanente del seno frontal atelectasiado hacia anterior (flecha) separado por el tabique de la celdilla SOE.

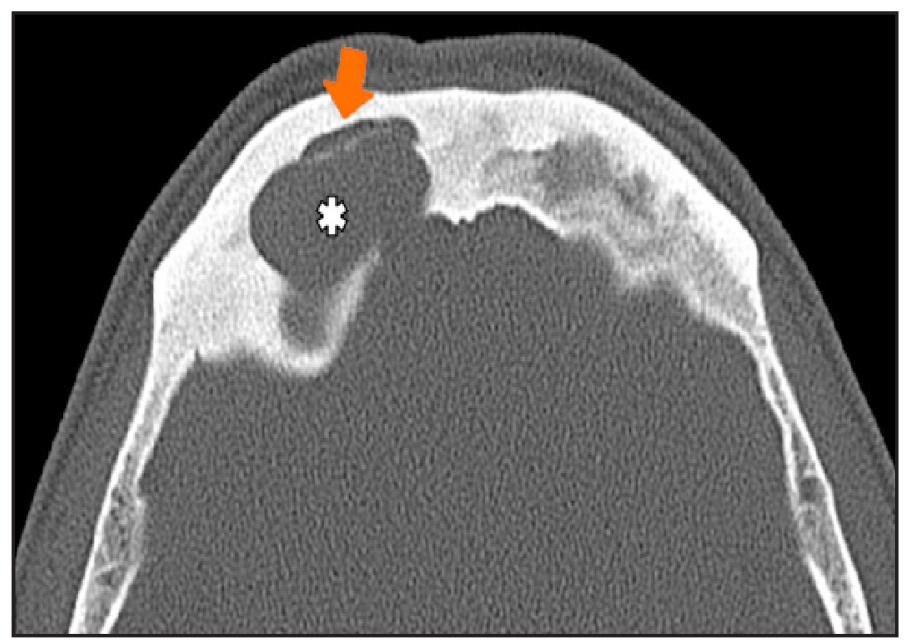




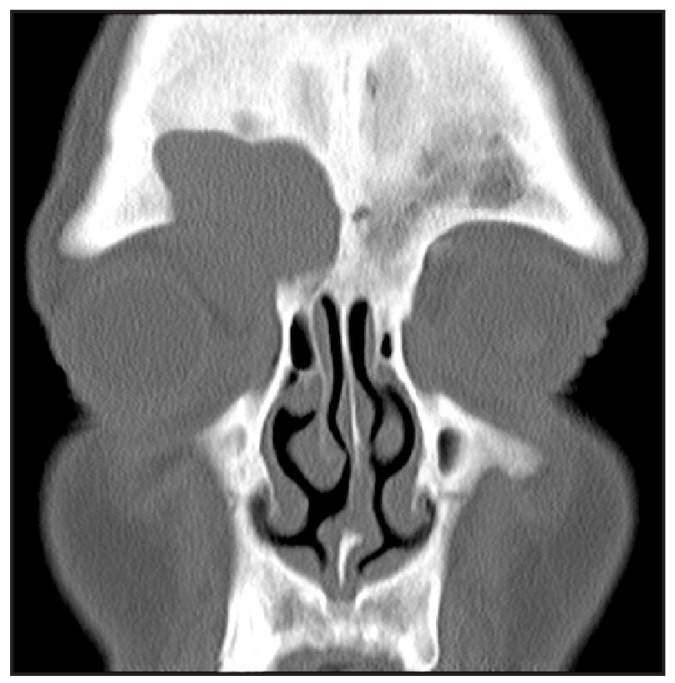

Figura 4. Corte coronal de CPN. Se visualiza el proceso expansivo a medial y superior de la órbita derecha en la zonal del seno frontal. En el lado izquierdo se observa seno frontal hipoplásico.

supializa nuevamente la celdilla SOE y se resecan focos de osteoneogénesis. Se identifica la arteria etmoidal anterior (Figura 6). Se repermeabiliza el

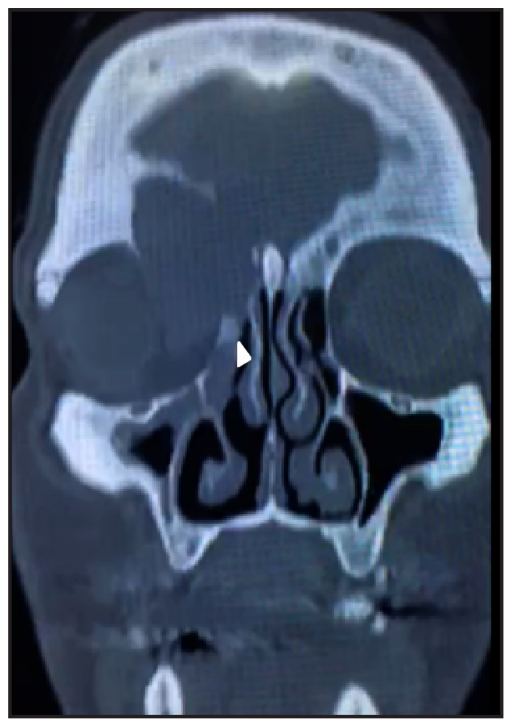

Figura 5. Corte coronal de TC de CPN. Se observa osteoneogénesis (flecha) que obstruye drenaje de la celdilla SOE.

drenaje de la celdilla (Figuras 7,8 y 9) y se logra acceder al seno frontal (Figuras 10 y 11) que se encuentra comprimido por la celdilla SOE.

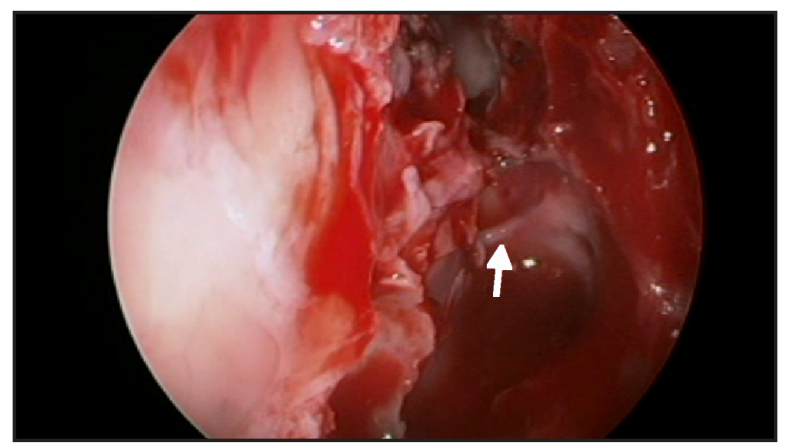

Figura 6. Arteria etmoidal anterior (flecha), posterior a la celdilla SOE.

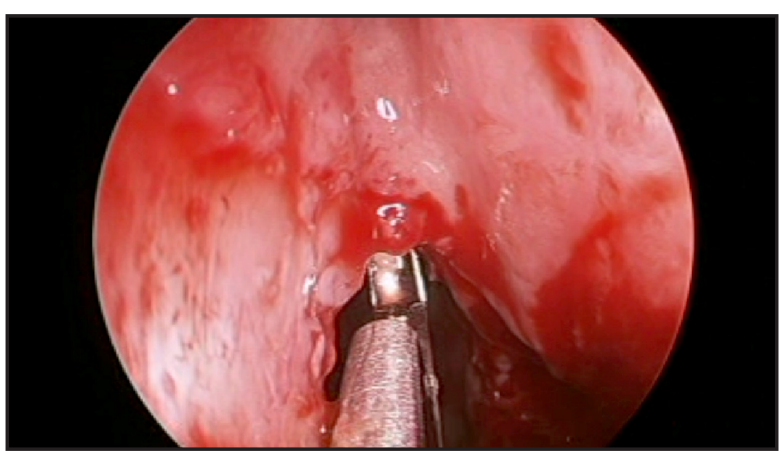

Figura 7. Apertura de la celdilla SOE, con pinza Kerrisson angulada. 


\section{DISCUSIÓN}

Los estudios publicados sobre la incidencia de la celdilla SOE en la población son realizados de manera retrospectiva en centros de referencia terciarios, en donde la población estudiada puede constituir una muestra de pacientes con complicaciones derivadas de una mayor presencia de la celdilla SOE, lo que constituiría un sesgo de selección llevando a una sobreestimación de la incidencia de la celdilla en la población.

El estudio de las imágenes, teniendo en cuenta los marcadores que indican la presencia de la celdilla SOE, permite una mejor aproximación y planificación previa a la cirugía.

Conocer la presencia de la celdilla SOE a priori en la cirugía endoscópica del seno frontal, resultaría en una menor incidencia de cirugía secundaria por estenosis 0 presencia de tejido cicatricial.

Del mismo modo lograr una adecuada permeabilidad en el área permitiría una mejor transmisión de flujos en las terapias médicas en el posoperatorio, disminuyendo el riesgo de enfermedad crónica refractaria.

En nuestro caso tuvimos una reestenosis en 2 oportunidades del drenaje realizado, Io cual podría explicarse entre otras cosas, por la actividad laboral del paciente (trabajador de la construcción con exposición permanente a irritantes). Después de la última intervención se sugiere cambio de actividad, sin haber recidiva hasta el momento.

La presencia de la celdilla SOE, agrega una mayor complejidad en el desafío quirúrgico del abordaje del seno frontal, por lo que su adecuado reconocimiento es fundamental.

\section{CONCLUSIONES}

El conocimiento de la anatomía del complejo etmoidal y de las celdillas que forman parte de él, como la SOE es importante en el manejo de lesiones que comprometen el seno frontal.

Es importante reconocer la proptosis como signo clínico de la presencia de una

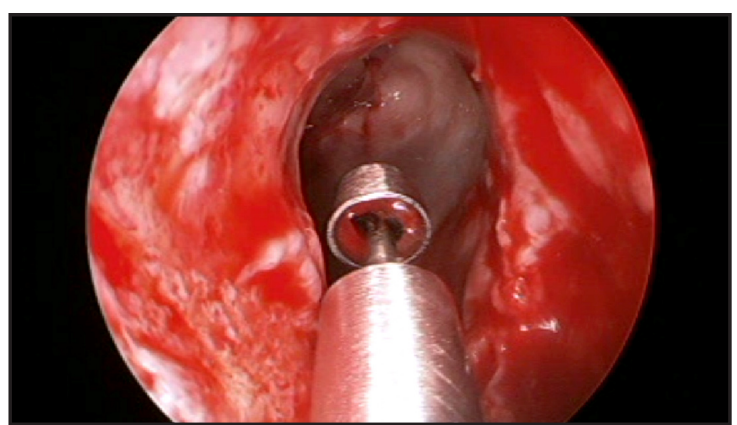

Figura 8. Apertura de la celdilla SOE, con pinza Mushroom angulada.

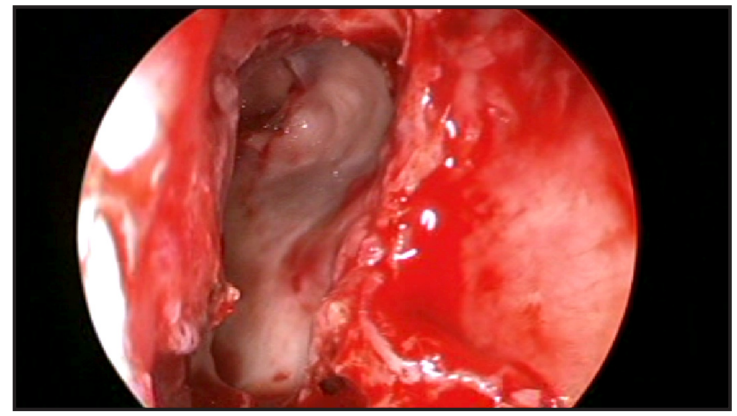

Figura 9. Celdilla SOE abierta.

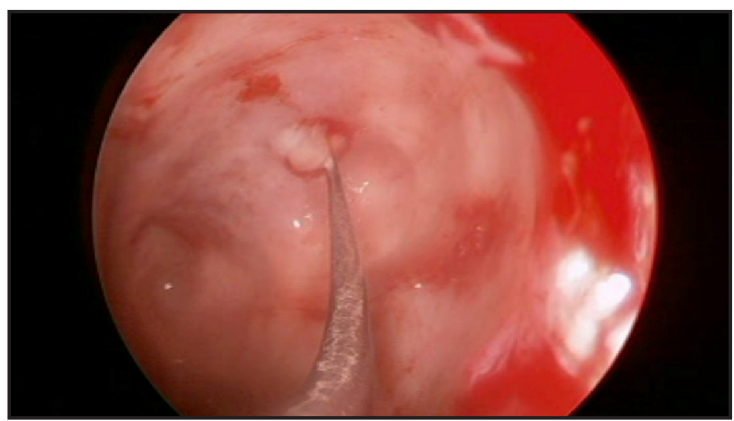

Figura 10. Apertura con tactador de seno frontal atelectasiado, se observa salida de secreción.

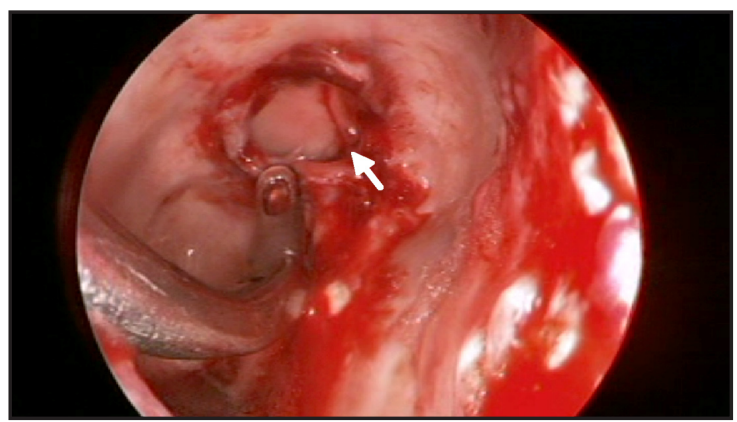

Figura 11. Interior de la celdilla SOE, hacia anterior se observa seno frontal abierto (flecha). 
celdilla SOE en casos de mucoceles en el complejo frontoetmoidal.

Se sugiere tener presente la presencia de septos en el seno frontal que puedan indicar la existencia de la celdilla SOE en la planificación de la cirugía endoscópica funcional.

En presencia de una celdilla SOE, es posible utilizarla como marcador para la ubicación de la

\section{BIBLIOGRAFÍA}

1. Zhang Luo, Demin Huan. Computed tomographic and endoscopic analysis of supraorbital ethmoid cells. Otolaryngology-Head and Neck Surgery 2007; 137: 562-8.

2. Comer BT, Nathan W. Kountakis SE. Frontal Sinus Septations Predict the Presence of Supraorbital Ethmoid Cells. Laryngoscope 2013; 123: 20903.

3. Simmen D, Raghavan U. The surgeon's view of the anterior ethmoid artery. Clin Otolaryngol 2006; 31: 187-91.

4. Jang D, Lachanas V, Kountakis S. Supraorbital Ethmoid Cell: A Consistent Landmark for Endoscopic Identification of the Anterior Ethmoidal Artery. Otolaryngology-Head and Neck Surgery 2014; 151 (6): 1073-7.

5. BнATt NJ, YARDIMCI S. Supraorbital ethmoidal cell: Anatomical prevalence and surgical significance. arteria etmoidal anterior en la cirugía endoscópica funcional.

Por estos antecedentes sería de relevancia estudiar la presencia de la celdilla SOE en la población latinoamericana, y en especial en nuestra población.

Las imágenes utilizadas se publican con autorización del paciente.

Otolaryngology - Head and Neck Surgery 2004; 131(2): P52-P53.

6. McMains C, Kountakis S. Fronto-orbital-ethmoid mucoceles. K. Operative Techniques in Otolaryngology 2006; 17: 19-23.

7. Comer BT, Nathan W Kincaid BS and, Kountakis S. The association between supraorbital ethmoid air cells and orbital proptosis in patients with chronic rhinosinusitis. International Forum of Allergy \& Rhinology 2013; 3(2): 147-9.

8. Comer BT, Nathan W. Kountakis S. Frontal Sinus Septations Predict the Presence of Supraorbital Ethmoid Cells. Laryngoscope 2013; 123: 2090-3.

9. Chiu AG, Vaughan WC. Management of the Lateral Frontal Sinus Lesion and the Supraorbital Cell Mucocele. American Journal of Rhinology 2004; 18(2): 83-6.

10. Friedel M, Shawn Li, Langer P, et al. Modified Hemi-Lothrop Procedure for Supraorbital Ethmoid Lesion Access. Laryngoscope 2012; 122: 442-4.

Dirección: Rodolfo Nazar S.

Hospital Clínico de la Universidad de Chile

Santos Dumont 999, Independencia. Santiago, Chile

E mail: rnazars@gmail.com 